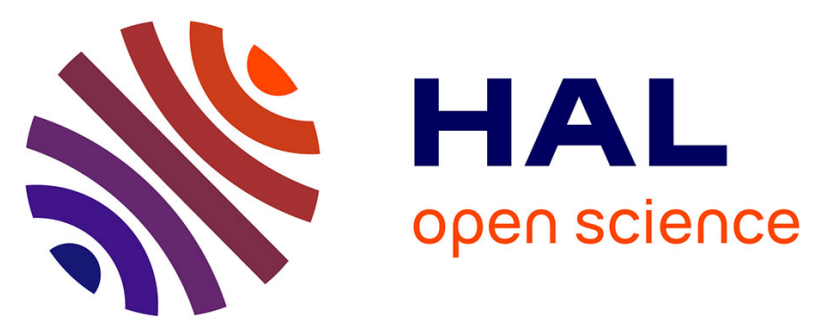

\title{
Tintigny meteorite: the first Belgian achondrite
}

Hamed Pourkhorsandi, Vinciane Debaille, J. Gattacceca, Richard Greenwood, Thierry Leduc, Marleen de Ceukelaire, Sophie Decrée, Steven Goderis

\section{To cite this version:}

Hamed Pourkhorsandi, Vinciane Debaille, J. Gattacceca, Richard Greenwood, Thierry Leduc, et al.. Tintigny meteorite: the first Belgian achondrite. Planetary and Space Science, 2021, 209, pp.105372. 10.1016/j.pss.2021.105372 . insu-03517363

\section{HAL Id: insu-03517363 https://hal-insu.archives-ouvertes.fr/insu-03517363}

Submitted on 18 Jan 2022

HAL is a multi-disciplinary open access archive for the deposit and dissemination of scientific research documents, whether they are published or not. The documents may come from teaching and research institutions in France or abroad, or from public or private research centers.
L'archive ouverte pluridisciplinaire HAL, est destinée au dépôt et à la diffusion de documents scientifiques de niveau recherche, publiés ou non, émanant des établissements d'enseignement et de recherche français ou étrangers, des laboratoires publics ou privés. 


\section{Journal Pre-proof}

Tintigny meteorite: The first Belgian achondrite

Hamed Pourkhorsandi, Vinciane Debaille, Jérôme Gattacceca, Richard Greenwood, Thierry Leduc, Marleen De Ceukelaire, Sophie Decrée, Steven Goderis

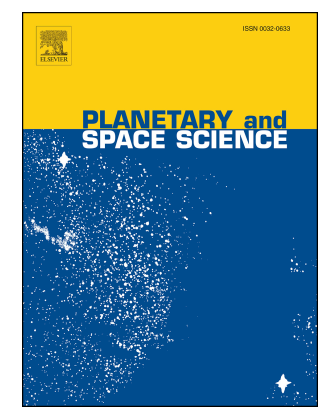

PII:

S0032-0633(21)00211-7

DOI:

https://doi.org/10.1016/j.pss.2021.105372

Reference: PSS 105372

To appear in: Planetary and Space Science

Received Date: 19 March 2021

Revised Date: 18 October 2021

Accepted Date: 27 October 2021

Please cite this article as: Pourkhorsandi, H., Debaille, V., Gattacceca, Jéô., Greenwood, R., Leduc, T., De Ceukelaire, M., Decrée, S., Goderis, S., Tintigny meteorite: The first Belgian achondrite, Planetary and Space Science (2021), doi: https://doi.org/10.1016/j.pss.2021.105372.

This is a PDF file of an article that has undergone enhancements after acceptance, such as the addition of a cover page and metadata, and formatting for readability, but it is not yet the definitive version of record. This version will undergo additional copyediting, typesetting and review before it is published in its final form, but we are providing this version to give early visibility of the article. Please note that, during the production process, errors may be discovered which could affect the content, and all legal disclaimers that apply to the journal pertain.

() 2021 Published by Elsevier Ltd. 


\section{Title: Tintigny meteorite: the first Belgian achondrite}

Authors: Hamed Pourkhorsandiaל ${ }^{2}$, Vinciane Debaille ${ }^{\mathrm{a}}$, Jérôme Gattacceca ${ }^{\mathrm{b}}$,

Richard Greenwood ${ }^{c}$, Thierry Leduc ${ }^{d}$, Marleen De Ceukelaire ${ }^{d}$, Sophie

Decrée $^{d}$, and Steven Goderis ${ }^{e}$

aLaboratoire G-Time, Université Libre de Bruxelles, CP 160/02, 50, Av. F.D.

Roosevelt, 1050 Brussels, Belgium

${ }^{b}$ CNRS, Aix-Marseille Univ, IRD, INRAE, CEREGE, Aix-en-Provence, France

'School of Physical Sciences, The Open University, Walton Hall, Milton Keynes, MK7

6AA, United Kingdom

${ }^{d}$ Royal Belgian Institute of Natural Sciences, Geological Survey of Belgium, 1000

Brussels, Belgium

eDepartment of Chemistry, Research Unit: Analytical, Environmental and Geo-

Chemistry, Vrije Universiteit Brussel, Brussels, 1050, Belgium

${ }^{4}$ Corresponding author. E-mail address: hamed.pourkhorsandi@ulb.ac.be

Revision to be submitted to the Planetary and Space Science (Planet Space Sci.)

Version: 18/10/2021 


\section{Abstract:}

A late afternoon in February 1971, a meteorite impacted the rooftop of a house in Tintigny village in southern Belgium. Confirmed as a possible meteorite by the schoolteacher, the meteorite and its fall story did not leave the village. Finally, 46 years after the fall event, we got the opportunity to study and characterize this meteorite. In this work, we give a detailed report on its textural, mineralogical, whole-rock elemental and oxygen isotopic composition. Officially named as Tintigny, we classified it as an achondrite from howarditeeucrite-diogenite (HED) clan and more precisely a polymict eucrite. A brecciated basaltic rock believed to be originated from the surface of V-type asteroids namely the asteroid 4-Vesta. Tintigny has recorded the evidence of the impact metamorphism and metasomatism processes active on its parent body. Tintigny is one of the 39 eucrite falls known to date, and one of the 11 eucrites occurred in Europe. It is the fifth officially recognized meteorite and the first achondrite from Belgium. This report shows the importance of studying and accessing such a meteorite for further cosmochemical and planetary investigations and enriching our knowledge on the formation of HED meteorites and their parent bodi(es). In addition, it brings the attention to its importance as a scientific heritage that has to be properly understood and safeguarded for the generations of scientists, scholar, and amateurs to come

Keywords: Achondrite, Fall, Eucrite, Belgium, Tintigny 


\section{INTRODUCTION}

In February 1971 (precise date not recorded), Mr Eudore Schmitz was working in his barn in the village of Tintigny (southern Belgium, $49.683786^{\circ} \mathrm{N}$, $5.532957^{\circ} \mathrm{E}$ ) during the late afternoon when he heard a loud noise from the roof of the building. After going upstairs, he found a hole in a tile and a black stone on the barn floor. It was suggested that he burnt himself picking up the fragment, so he used some hay and then his hat to hold the stone. The schoolteacher of the village, Mr Albert Rossignon, confirmed that the stone was a meteorite and kept it, hoping that his identification would be confirmed during a subsequent investigation. The teacher later joined a religious seminary and became a priest. While he faithfully kept the meteorite and showed it from time to time to visitors and children, the stone and associated story never left the region. In 2017, after reading an article about recent Belgian meteorite recovery expeditions in Antarctica, he contacted Dr Vinciane Debaille, professor at the Université Libre de Bruxelles (ULB) and specialist in planetary sciences and meteoritics who recognized the stone as an achondritic meteorite. The meteorite was subsequently donated by Madam Germaine Mathus, widow of Mr Eudore Schmitz, and her children, Jean-Paul, Rita and Joseph Schmitz, to the Royal Belgian Institute for Natural Science (RBINS) and studied. While the meteorite is no longer complete due to handling of the stone by various people over the years, Father Rossignon affirms that the fusion crust was initially complete, with a piece of the tile originally stuck on the stone. 
We have classified this meteorite as a polymict eucrite and Tintigny, its

Figure 1: Meteorites of Belgium with fall/find years and types. official name, has been approved by the Nomenclature Committee of the

Meteoritical Society (Gattacceca et al., 2020). Tintigny is the fifth officially

recognized meteorite and the first achondrite from the Belgian territory (Fig. 1).

This meteorite is now on permanent open display at RBINS.

In this paper, details on the petrological, geochemical, and isotopic

characteristics of Tintigny are reported and its formation processes studied.

St. Denis Westrem

Tourinnes-la-Grosse

1863, L6

Hautes Fagnes

1965, LL5

\section{Lesves}

1896, L6

\section{BELGIUM}

\section{Tintigny}

1971, Eucrite
1855, L6 Brussels 
Following examination of the whole rock using a stereomicroscope, representative fragments covering all petrographic textures were separated and embedded in resin at RBINS. Mineralogical and petrological studies were conducted using an optical microscope (ULB) and a PANalytical (Quanta 200) equipment Environmental Scanning Electron Microscope (ESEM) equipped with an EDAX (Apollo 10 silicon drift detector) Energy Dispersive Spectrometer (EDS) at the RBINS. The chemical composition of mineral phases were determined using a CAMECA SX50 electron microprobe (EMP) at the CAMPARIS facility (Paris), relying on a series of natural and synthetic standards and a later correction for $\mathrm{SiO}_{2}$ calibration. The set instrument parameters include a focused electron beam ( $1 \mu \mathrm{m}$ in diameter), an accelerating voltage of $15 \mathrm{kV}$ and a beam current of $10 \mathrm{nA}$. We aimed to analyze pyroxene and plagioclase with diverse compositions. Special care was considered to avoid grain boundaries, cracks etc. which can bias the quality of the analytical data. Whole-rock major and trace elemental concentrations were determined at the Laboratoire G-Time of the ULB, Belgium. Around $50 \mathrm{mg}$ of sample representing the most common lithology (light grey) of the meteorite, was dissolved by alkaline fusion for major and trace element contents. Major elements were measured using a Thermo Fisher Scientific iCAP inductively coupled plasma-optical emission spectrometer (ICP-AES) at ULB with Y as an internal standard. Overall, the total reproducibility estimated based on United States Geological Survey reference material BHVO-2 is calculated to be better than $2 \%$ relative standard deviation (RSD). Trace elements were measured 
using the Agilent 7700 Quadrupole-Inductively Coupled Plasma-Mass

Spectrometer (Q-ICP-MS) operated with a He-filled collision cell at ULB.

Indium was used as internal standard. The total reproducibility estimated based on USGS reference material BHVO-2 is calculated to be better than $10 \%$ relative standard deviation $(\mathrm{RSD})$.

High-precision oxygen isotopic analysis of Tintigny was undertaken at the Open University (Milton Keynes, UK) using an infrared laser-assisted fluorination system (Miller et al., 1999; Greenwood et al., 2017).

Measurements were made on a $200 \mathrm{mg}$ aliquot of silicates from the bulk sample. Approximately $2 \mathrm{mg}$ aliquots of samples and standards were loaded into a nickel sample block, which was then placed in a two-part chamber, made vacuum tight using a compression seal with a copper gasket and quickrelease KFX clamp (Miller et al., 1999). A $3 \mathrm{~mm}$ thick $\mathrm{BaF}_{2}$ window at the top of the chamber allows simultaneous viewing and laser heating of samples.

Prior to analysis the sample chamber was heated overnight under vacuum to a temperature of about $70^{\circ} \mathrm{C}$ to remove any adsorbed moisture. Following overnight heating, the chamber was allowed to cool to room temperature and was then flushed with several aliquots of $\mathrm{BrF}_{5}$. The system was then left to pump for at least a further 24 hours and oxygen isotopic analysis was only undertaken when the blank level reached $<60$ nanomoles of $\mathrm{O}_{2}$. Sample heating in the presence of $\mathrm{BrF}_{5}$ was carried out using a Photon Machines Inc. $50 \mathrm{~W}$ infrared $\mathrm{CO}_{2}$ laser $(10.6 \mu \mathrm{m})$ mounted on an $\mathrm{X}-\mathrm{Y}-\mathrm{Z}$ gantry. Reaction progress was monitored by means of an integrated video system. After 
fluorination, the released $\mathrm{O}_{2}$ was purified by passing it through two cryogenic nitrogen traps and over a bed of heated $\mathrm{KBr}$ to remove any excess fluorine. The isotopic composition of the purified oxygen gas was analyzed using a Thermo Fisher MAT 253 dual inlet mass spectrometer with a mass resolving power of approximately 200.

Overall system precision, as defined by replicate analyses of our internal obsidian standard, is: $\pm 0.053 \%$ for $\delta^{17} \mathrm{O} ; \pm 0.095 \%$ for $\delta^{18} \mathrm{O} ; \pm 0.018 \%$ for $\Delta^{17} \mathrm{O}$ $(2 \sigma)$ (Starkey et al., 2016). Oxygen isotopic analyses are reported in standard $\delta$ notation, where $\delta^{18} \mathrm{O}$ has been calculated as: $\delta^{18} \mathrm{O}=\left[\left({ }^{18} \mathrm{O} /{ }^{16} \mathrm{O}\right)\right.$ sample $/\left({ }^{18} \mathrm{O}\right.$ $\left.{ }^{16} \mathrm{O}\right)$ VSMOW -1] $1000(\%)$ and similarly for $\delta^{17} \mathrm{O}$ using the ${ }^{17} \mathrm{O} /{ }^{16} \mathrm{O}$ ratio. VSMOW is the international standard Vienna Standard Mean Ocean Water. $\Delta{ }^{17} \mathrm{O}$, which represents the deviation from the terrestrial fractionation line, has been calculated using the linearized format of Miller (2002):

$$
\Delta^{17} \mathrm{O}=1000 \ln \left(1+\left(\delta^{17} \mathrm{O} / 1000\right)\right)-\lambda 1000 \ln \left(1+\left(\delta^{18} \mathrm{O} / 1000\right)\right) \text { where } \lambda=
$$

\subsection{7.}

\section{RESULTS}

\section{Macroscopic description}

As a result of the thermal effects experienced during atmospheric entry and impact through the roof of the building, the Tintigny meteorite finally fragmented into several pieces during its extensive manual handling alongside fractures, indicated by the occurrence of broken surfaces. The single recovered fragment weighs $210 \mathrm{~g}$ (Fig. 2). 
The meteorite is partly covered by a shiny black fusion crust, which varies in thickness depending on the morphology of the underlying surface. Three main varieties of fusion crust are present: (i) the thickest ( 1-2 $\mathrm{mm})$ parts that occur

130 in hollow areas of the surface and display a wavy texture comprising elevated

131 ribbons of molten material (flow lines) (Fig. 2a); (ii) the main part that is

132 considerably thinner $(\sim 0.5 \mathrm{~mm})$ and indicates a full layer of molten material

133 with a texture containing assemblages of crater-like pits (Fig. 2b); (iii) the

134 intermediate part exhibiting a combination of these two variations, with a 135 patchy texture occurring along the edges of the meteorite surface. Several

136 cracks occur on the surface of the fusion crust. They correspond to deeper

137 fractures visible where the surface is broken (Fig. 2c). At these sites, a light gray interior is revealed, composed of a fine-grained light-colored matrix hosting darker crystals and a cm-size dark grey clast (Fig 2d). Macroscopic observations indicate that Tintigny is a brecciated achondrite. 
a
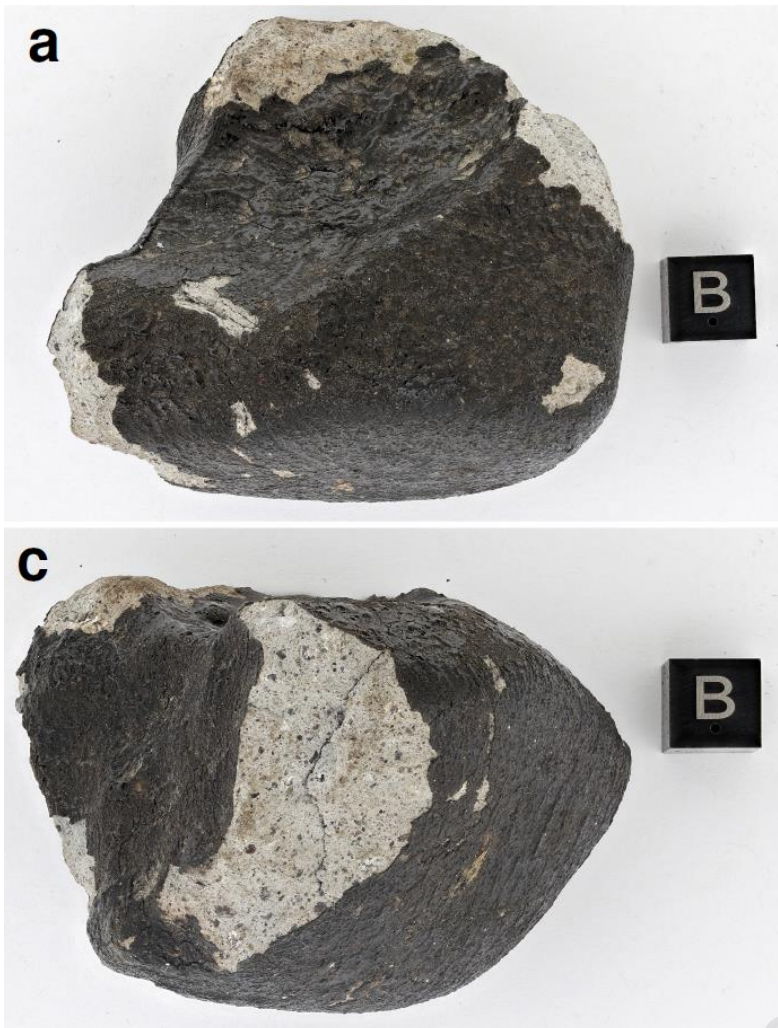

b

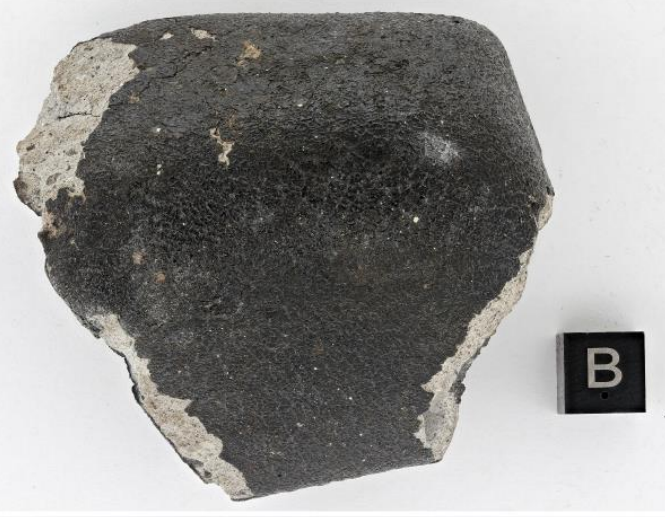

d

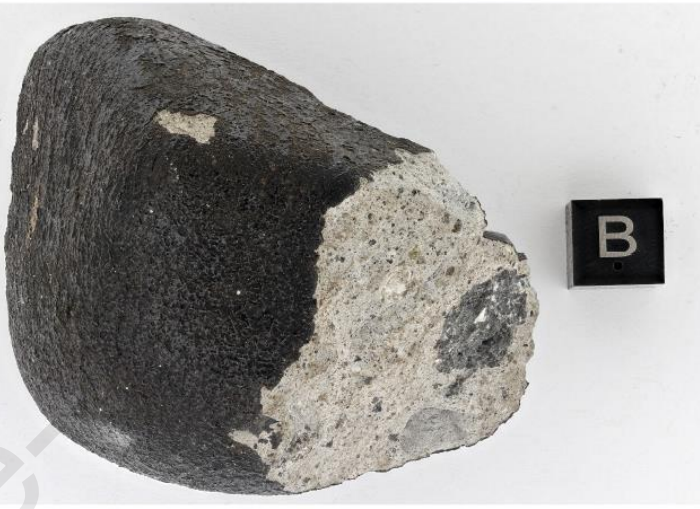

142

Figure 2: Tintigny meteorite from different angles. Note the different textures of fusion crust, the occurrence of fractures, and a dark grey clast in d. Image credit: RBINS.

\section{Microscopic description}

Using optical and electron microscopy, Tintigny exhibits a brecciated subophitic basaltic texture mainly composed of plagioclase/maskelynite and clinopyroxene (Fig. 3). These minerals occur both as large crystals $(>50 \mu \mathrm{m})$ and as smaller $(<50 \mu \mathrm{m})$ ones, the latter mainly composing the clastic matrix. Accessory minerals include troilite, ilmenite, chromite, (Fe,Ni) metal, and silica. Most of the minerals exhibit well-delineated edges, enhancing the clastic texture of the rock. At least two generations of shock fractures are visible: 
153

154

155

156

157

158

159

those specific to clasts and large crystals, and those cross-cutting both the larger grains and the matrix materials.

In addition to the main sub-ophitic texture, at least three distinct textures are present in specific clasts. These clasts are different from their host based on their texture and degree of equilibrium recorded in the composing minerals.

Figure $3 \mathrm{a}, 4 \mathrm{e}$ shows $\mathrm{a} \sim 1 \mathrm{~mm}$ long clast with a sub-ophitic texture. Elongated pyroxenes are unequilibrated and display Fe enriched rims. The elongation directions of pyroxene crystals control the alignment of plagioclase. Abundant cracks perpendicular to pyroxene elongation are visible. They are absent from the adjacent plagioclase crystals, suggesting elevated levels of mechanical stress prior plagioclase crystallization. Some of these plagioclase crystals are cut by randomly oriented cracks, which are filled by Fe-rich pyroxenes. This is related to fusion crust formation. Another clast with a similar texture is visible in Fig. 3f.

Under the electron microscope, the dark clast visible on the broken surface (Fig. 2d) displays a melt rock texture (Fig. 3e,4f). The groundmass is a mixture of quenched pyroxene and plagioclase and only a few larger grains including (Fe,Ni) metal, ilmenite, chromite, and an intergrowth of plagioclase-pyroxene are present.

A single $\sim 0.5 \mathrm{~mm}$ clast and several smaller grains exhibit a symplectitic mixture of pyroxene, fayalite, and silica (Fig. 3a,c,d and Fig. 4b,d).

A small number of pyroxenes show evidence of Fe enrichment along veins and crystal rims (Fig. 3f and Fig. 4b,e). These fractures are mostly limited to 

was prior to the assembly of Tintigny on its parent body.
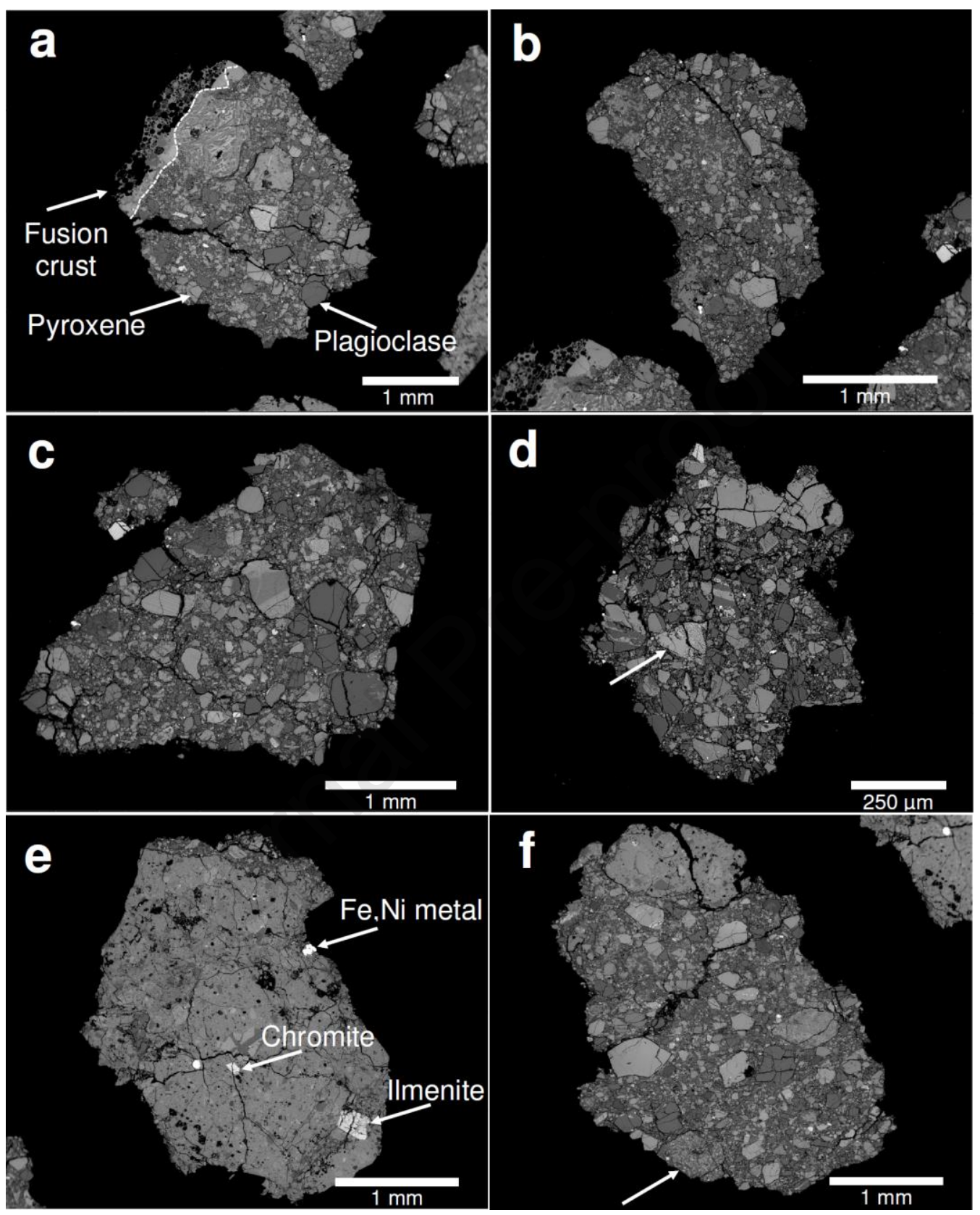

Figure 3: Backscattered electron microscope images of Tintigny. The presence of different textures suggests Tintigny to be a brecciated eucrite. a) A sub-ophitic clast adjacent to the fusion crust shows a texture distinct from that of the host. In the center, a clast with a symplectitic texture is visible. b) Typical texture of Tintigny. A pyroxene with exsolution lamellae is visible. c) Variety of pyroxene textures including exsolution lamella and symplectitic assemblages. d) Partial transformation of pyroxene to a symplectitic assemblage 

textural evidence of melt rock. f) The occurrence of different clasts. Note Fe-rich veins in a $500 \mu \mathrm{m}$ pyroxene in upper left. A clast with relatively larger crystals (shown with arrow) with similar sub-ophitic texture to the clast shown in $3 a$ and $4 \mathrm{e}$.

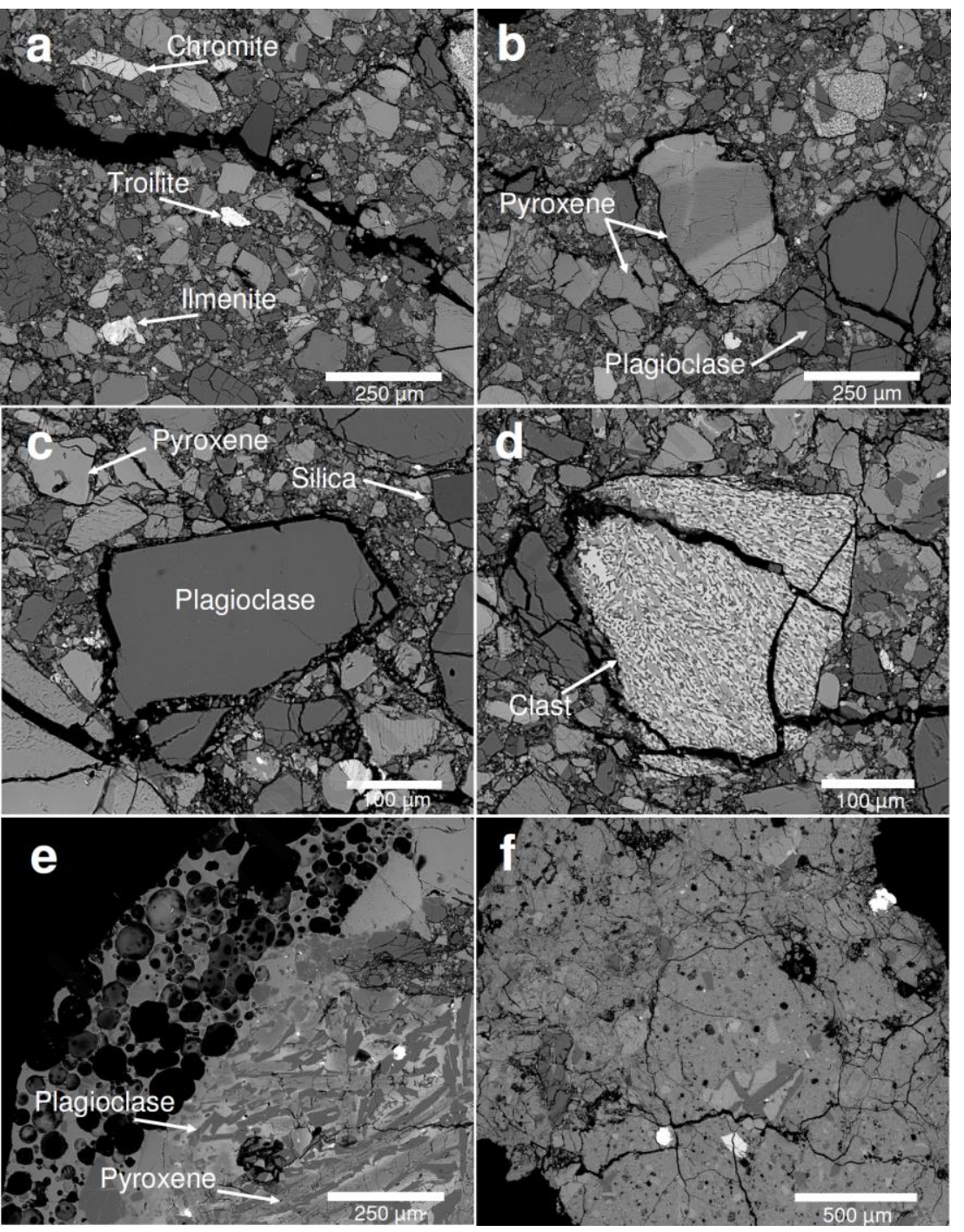

Figure 4: a) Accessory minerals in Tintigny. b) Pyroxene showing a variety of textures (exsolution, twinning, symplectitic, etc.), suggesting a complex thermal history experienced by the Tintigny. c) Clastic texture of Tintigny formed as a result of impact metamorphism on the parent body surface. d) A symplectitic assemblage of hedenbergite-fayalite-silica. e) Alignment of plagioclase along the surface of pyroxene. Note the higher concentration of $\mathrm{Fe}$ in pyroxene rims. f) A closer view of the dark grey clast (Fig. 2d) shows lower number of crystals and a shock-melted texture. 


\section{Mineral chemistry}

Table 1 summarizes the chemical composition of pyroxene and plagioclase crystals analyzed randomly in different fragments of Tintigny. Mineral chemistry calculations of pyroxene end members show ranges from 8.5 to 60.7 mol\% for enstatite, 30.1 to $70.0 \mathrm{~mol} \%$ for ferrosilite, and 2.6 to $38.4 \mathrm{~mol} \%$ for wollastonite. Based on these values, most pyroxenes in Tintigny are pigeonite and augite (Morimoto 1988; Marshall 1996) (Fig. 5a). The Fe/Mn ratios of pyroxenes range from 27.1 to 39.3 , with the highest ratio observed in pyroxene from the symplectitic clast (Pyx \#5, Table 1). Fe/Mn and Fe/Mg ratios in lowCa pyroxene (Wo $<10$, Pyx $\# 1,2,3,6,7,10$ ) are $30.2 \pm 4.4$ and $0.8 \pm 0.3$, respectively. These ratios in high-Ca pyroxene $(n=8)$ are $34.3 \pm 3.7$ for $\mathrm{Fe} / \mathrm{Mn}$ and 2.6 \pm 2.4 for $\mathrm{Fe} / \mathrm{Mg}$. The average pyroxene Fe/Mn ratio for all pyroxene is $32.5 \pm 4.4(\mathrm{SD}, \mathrm{n}=14)$. Fe/Mg ranges from 0.6 to 8.2 , with an average value of 1.8 $\pm 2.0(S D, n=14)$. Considering pyroxene Fe/Mn ranges of $40 \pm 11,62 \pm 18$, $32 \pm 6$, and $30 \pm 2$ for basaltic rocks from the Earth, Moon, Mars, and 4Vesta (eucrites), respectively, and based on our data, particularly those of low-Ca pyroxene, Tintigny falls in the range of basaltic eucrites (Papike et al., 2003). We believe the higher standard deviation of our data results from a higher diversity and relatively lower number of the analyzed minerals.

The anorthite content of four analyzed plagioclase ranges from 75.8 to 90.3 mol\%. Plagioclase in the symplectitic clast, with $75.8 \mathrm{~mol} \%$ anorthite, is less calcic (and more sodic) than the host (Fig. 5b). Excluding this clast, the anorthite percentage averages to $86.8 \pm 3.4 \mathrm{~mol} \%(\mathrm{SD}, \mathrm{n}=3)$. This value is in 
range of both vestan ( $87 \pm 2$ mole $\%)$ and lunar rocks (89 \pm 3 mole\%) (Papike et al., 2003), however the Fe/Mn ratio of pyroxene indicates that Tintigny is a member of the HED suit.
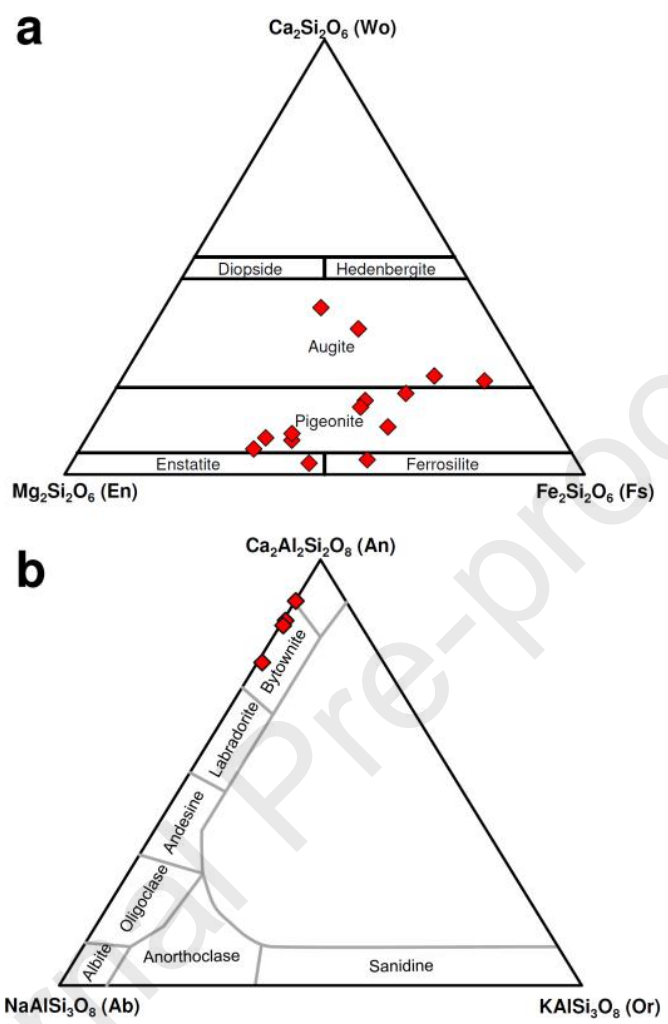

Figure 5: Pyroxene and plagioclase compositions in Tintigny.

\section{Whole-rock chemical composition}

Table 2 shows the major and trace element concentrations of Tintigny.

Based on bulk rock Fe/Mn vs. Fe/Mg ratios, three distinct zones for chondrites,

229 lunar rocks, and howardite-eucrite-diogenite (HED)/Martian meteorites can be

230 defined (Goodrich \& Delaney, 2000). For Tintigny, the bulk rock Fe/Mn and

$231 \mathrm{Fe} / \mathrm{Mg}$ ratios are 33.9 and 3.1, respectively. These values overlap with those measured for HED and Martian meteorites. To discriminate between different 
types of basaltic achondrites, Fe/Mn has previously been combined with other useful ratios such as $\mathrm{Ga} / \mathrm{Al}$ (Barrat et al., 2003). The $\mathrm{Ga} / \mathrm{Al}$ ratio of Tintigny is $4.17 \times 10^{-5}$, fully in range of those of eucrites (Fig. 6). The Cl-normalized elemental concentrations for Tintigny are compared to those of 18 noncumulate eucrites in Fig 7. The latter plot indicates the strong similarities between the chemical composition of Tintigny and that of noncumulate eucrites. This similarity to eucrites is also evident based on various combinations of major and trace elements for HED. On a binary plot of $\mathrm{Ca}$ versus Mg, Tintigny overlaps with eucrites, but is distinct from howardites or

242 diogenites (Fig. 8). Similar behavior occurs in Sm versus $\mathrm{Mg}$ and $\mathrm{Yb}$ versus $\mathrm{La}$ plots. Based on the abundance of $\mathrm{TiO}_{2}(0.63 \%)$ and $\mathrm{FeO} / \mathrm{MgO}$ ratio (2.66), Tintigny is a member of non-cumulate eucrites (Fig. 9) (Barrat et al., 2003).

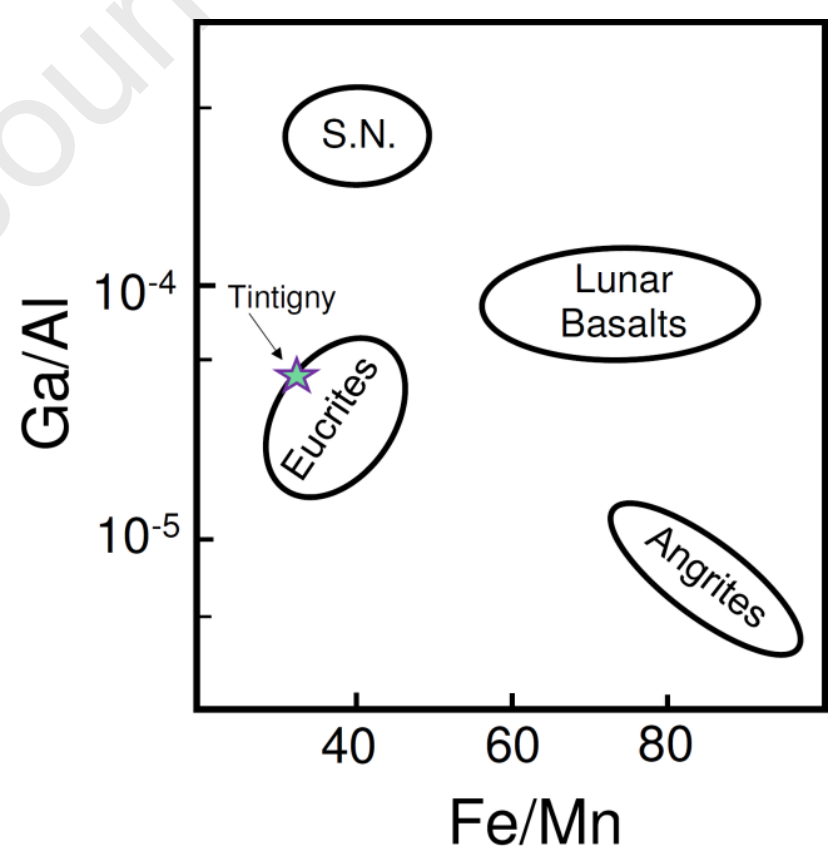


Figure 6: $\mathrm{Ga} / \mathrm{Al}$ vs. Fe/Mn of Tintigny in comparison to other basaltic meteorites. Plot modified from Barrat et al. (2003). S.N. stands for shergottites and nakhlites clan of Martian meteorites.

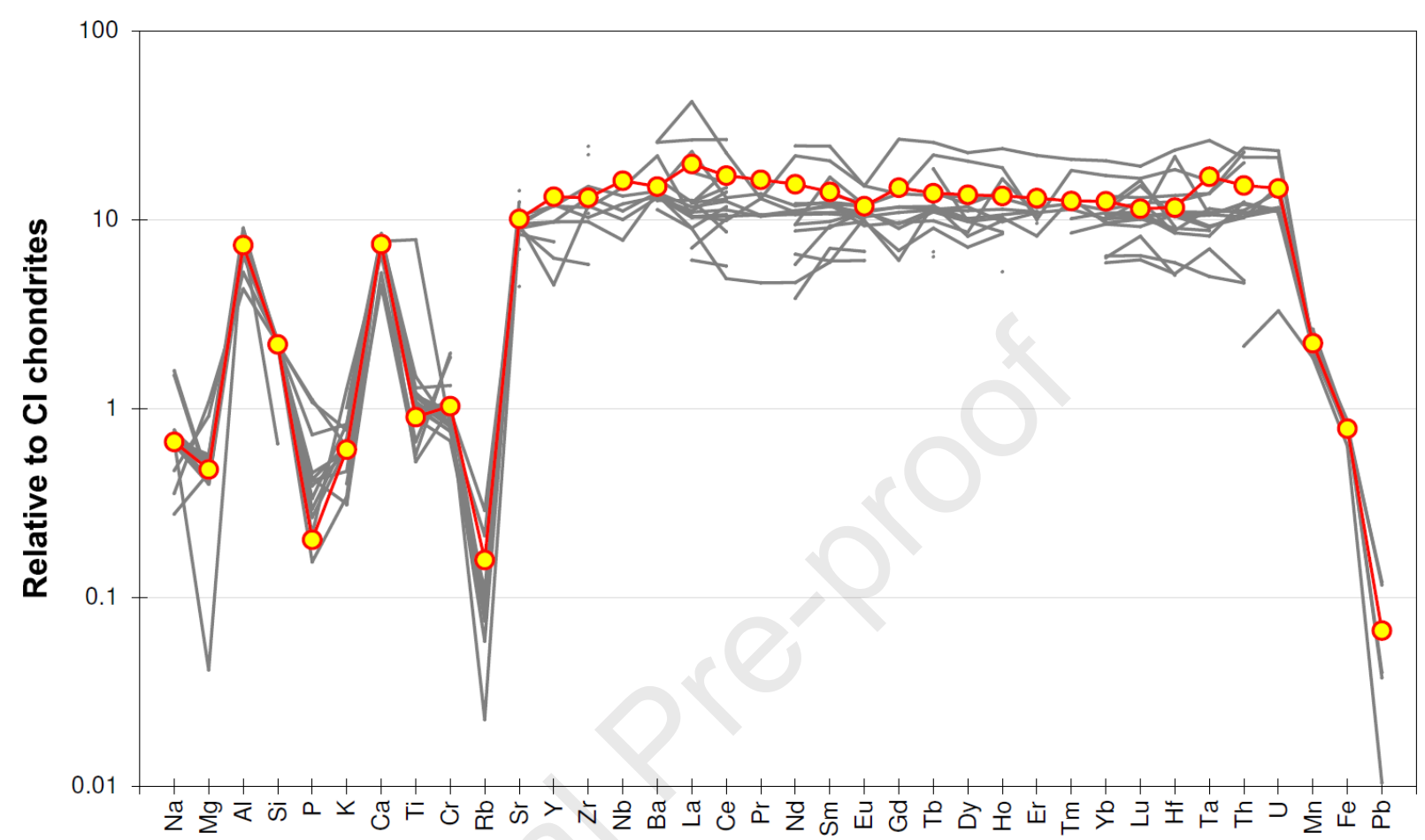

251 Figure 7: Cl-normalized whole-rock chemical composition of Tintigny and 18 noncumulate eucrites (Béréba, Bouvante, Cachari, Chervony Kut, Elephant Moraine A79004,A79005, Haraiya, Ibitira, Junzac, Juvinas, Millbillillie, Moore County, Pasamonte, Pomozdino, Yamato $254794002,791573,82049,82202)$. Eucrite data from Kitts \& Lodders (1998), Mittlefehldt (2015). Average Cl chondrite data are from Wasson \& Kallemeyn (1988). Lithophile, siderophile, and chalcophile elements are shown with increasing atomic number, respectively. 

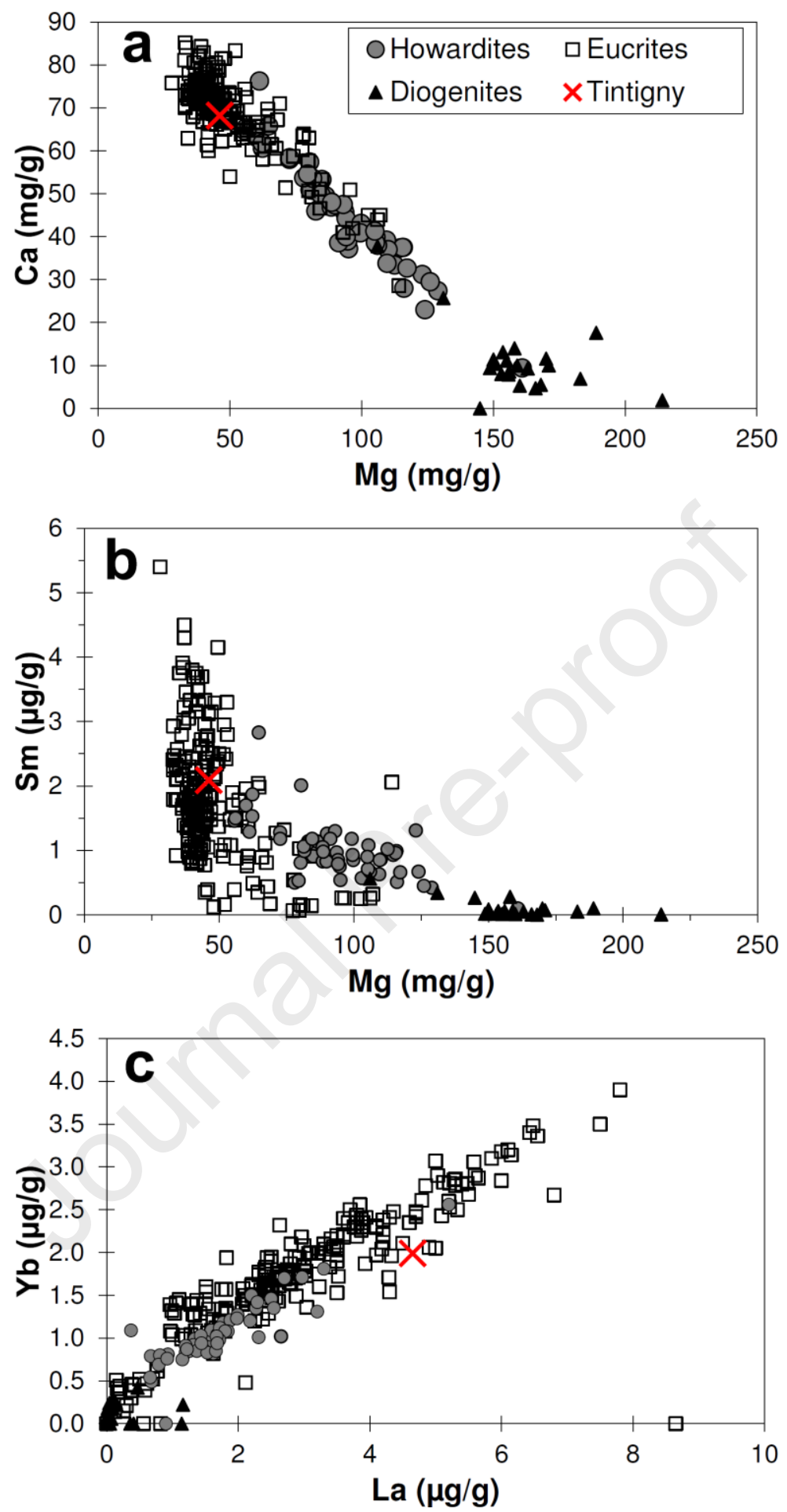

258 Figure 8: The abundance of Mg vs. Ca, Mg vs. Sm., and La vs. Yb for Tintigny in relation to howardite-eucrite-diogenite (HED) meteorites. Compilation of HED data by Mittlefehldt (2015). 


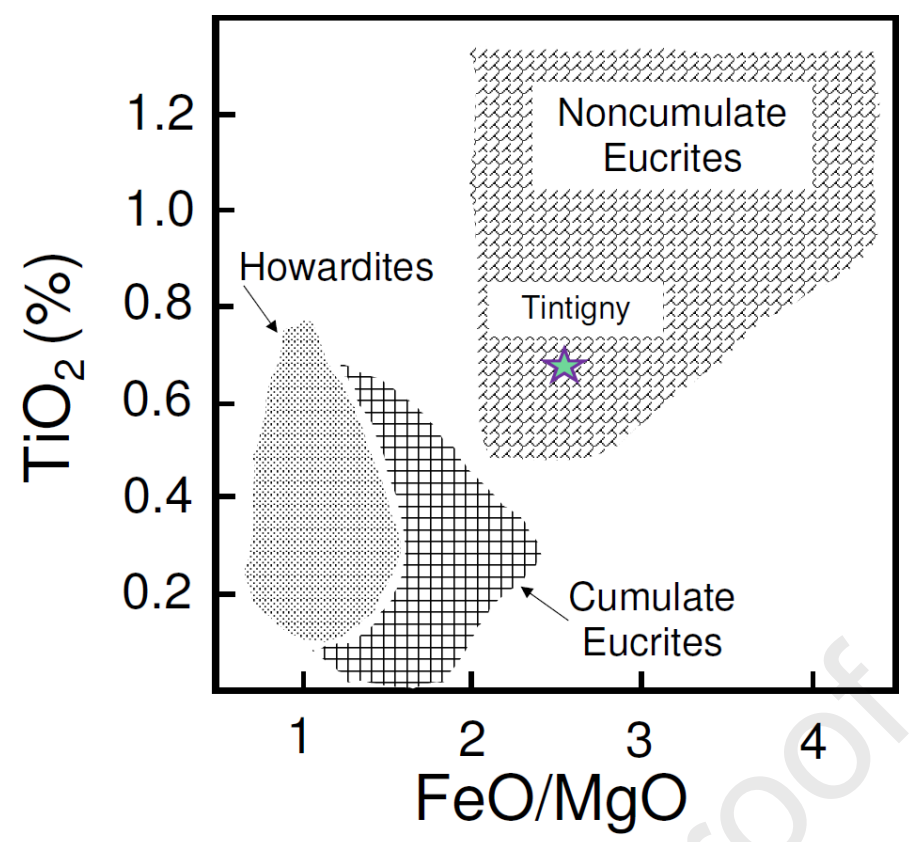

Figure 9: $\mathrm{TiO}_{2}$ vs. FeO/MgO of Tintigny in comparison to howardite and eucrites. Plot modified from Barrat et al. (2003).

\section{Oxygen isotopic composition}

266 Two replicate analyses Tintigny gave the following oxygen isotopic: $\delta^{17} \mathrm{O}=$

$1.723 \pm 0.018(1 \sigma) ; \delta^{18} \mathrm{O}=3.756 \pm 0.041(1 \sigma)$ and $\Delta^{17} \mathrm{O}=-0.246 \pm 0.003(1 \sigma)$.

268 The oxygen isotope data for Tintigny are plotted in relation to the HED data of

269 Greenwood et al. (2017) in Fig. 10 and this shows that the meteorite lies close

270 to the Eucrite Fractionation Line (EFL) defined by eucrite and diogenite falls

$271\left(\Delta^{17} \mathrm{O}=-0.240\right)$. In addition, the $\delta^{18} \mathrm{O}$ value of Tintigny plots centrally in the

272 field of eucrite analyses. The oxygen isotopic data is therefore consistent with

273 the classification of Tintigny as a eucrite. 


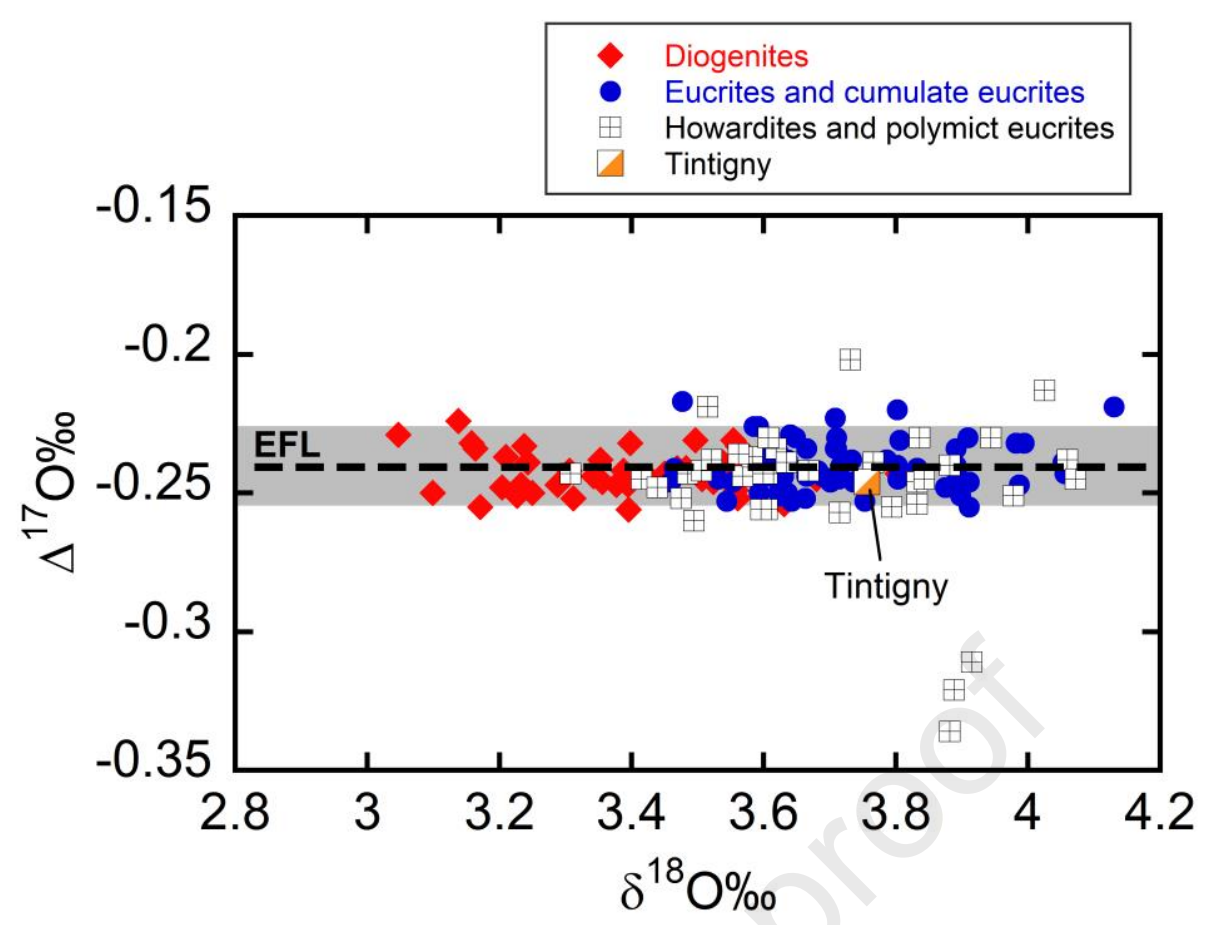

Figure 10: Oxygen isotopic composition of Tintigny in comparison with HED meteorites. HED data from Greenwood et al. (2017).

\section{DISCUSSION AND CONCUSIONS}

In this work, we used petrography, mineralogy, and whole-rock major and trace-element chemistry to classify the Tintigny meteorite. In addition, we have undertaken oxygen isotope analysis which has confirmed that Tintigny is a member of the HED clan. Based on our studies we conclude that Tintigny is a non-cumulate eucrite, specifically a polymict basaltic eucrite.

Eucrites, together with howardites and diogenites, form the HED clan that constitutes $74.6 \%$ by number of all achondrites, and $3.6 \%$ by number of all meteorites in meteorite collections worldwide (Meteoritical Bulletin Database

287 (https://www.Ipi.usra.edu/meteor/metbull.php), accessed February 2021). 
Based on the spectral data obtained in the laboratory and their comparison with data measured by ground-based observatories and the results from the NASA Dawn mission, HEDs are thought to originate from differentiated asteroids with V-type spectra, and in particular 4-Vesta (McSween et al., 2010; Moskovitz et al. 2010). Postcrystallization events on the parent body such as thermal metamorphism, metasomatism, shock metamorphism, and space weathering have led to the formation of rocks with complex geological histories (Yamaguchi et al., 1994; Takeda et al., 1985; Warren et al., 2014). As described earlier, Tintigny has also been affected by these processes, in particular thermal and shock metamorphism and possibly metasomatism as recorded in some grains (as Fe enrichment along veins and crystal rims). Many HED meteorites are brecciated, with a general distinction between 
311

the formation of Fe enrichment along the veins and crystal rims to fluid-driven alteration on the parent body surface.

Diogenites are mostly orthopyroxene cumulates that formed in plutons which crystallized at varying levels within the crust. Eucrites are mostly basaltic rocks that formed at faster cooling rates, most likely as a result of emplacement either on the surface or at shallow depths. According to their textural and compositional characteristics eucrites can be further divided into basaltic rocks (mostly monomict breccias), cumulate gabbros, and polymict eucrites made of different eucritic textures (without diogenitic clasts) like Tintigny (Vollmer et al., 2020). Barrat et al. (2003) also divides them to cumulate and noncumulate eucrites. Howardites formed as the products of impact events on the parent body surface, occurring as breccias made from different percentages of eucritic and diogenitic materials.

Meteoritical Bulletin Database (https://www.lpi.usra.edu/meteor/metbull; August 2021) lists 2447 HED meteorites encompassing 1516 eucrites, 399 howardite, and 532 diogenites. Out of this number, only 69 of the HED are falls, i.e., meteorites that have been observed falling and have been collected soon after their impact, avoiding the detrimental effects of terrestrial weathering, which are common in meteorite finds (meteorites without any fall record) and even in some cases in falls if not collected immediately (Walker et al., 2018; Pourkhorsandi, 2018; Pourkhorsandi et al., 2019). Including Tintigny, only 39 eucrite falls are known to date, 11 of them occurred in Europe and Tintigny being the only one from Belgium. This highlights the importance of 
classification and accessibility of such a meteorite for further cosmochemical and planetary studies and enriching our knowledge on the formation of HED meteorites and their parent bodi(es). In addition to its scientific importance, we emphasize the importance of the discovery of a historical meteorite fall in bringing attention to national scientific heritage that has to be properly understood and safeguarded for the generations of scientists, scholar, and amateurs to come (Franza \& Pratesi, 2021).

\section{Acknowledgments}

We all warmly thank the Schmitz family for their donation of the meteorite to the RBINS. We thank W. Debouge, S. Cauchies, and J. de Jong for their support in the clean labs and analysis facilities at the Laboratoire G-Time. We appreciate constructive comments by the two anonymous reviewers and editorial handing by Dr. A.P. Rossi.

This project has received funding from the European Union's Horizon 2020 research and innovation programme under the Marie Skłodowska-Curie grant agreement No 801505. VD thanks the ERC StG "ISoSyC" and FRS-FNRS for funding. SG, SD and VD thank the Brain-be Belspo projects BAMM and DESIRED for funding.

\section{References}


Barrat J.A., Jambon A., Bohn M., Blichert-Toft J., Sautter V., Gopel C., Gillet Ph. Boudouma O., and Keller F. 2003. Petrology and geochemistry of the unbrecciated achondrite Northwest Africa 1240 (NWA 1240): An HED parent body impact melt. Geochimica et Cosmochimica Acta 67:3959-3970.

Barrat J.A., Yamaguchi Y., Bunch T.E., Bohn M., Bollinger C., and Ceuleneer G. 2011. Possible fluid-rock interactions on differentiated asteroids recorded in eucritic meteorites. Geochimica et Cosmochimica Acta 75:3839-3852.

Franza A. and Pratesi G. 2021. Meteorites as a scientific heritage. Conservar Património 36:106-121.

Gattacceca J., McCubbin F. M., Bouvier A., and Grossman J. 2020. The meteoritical Bulletin No. 107. Meteoritics \& Planetary Science 55:460-462.

Goodrich C. and Delaney J. 2000. Fe/Mg-Fe/Mn relations of meteorites and primary heterogeneity of primitive achondrite parent bodies. Geochimica et Cosmochimica Acta 64:149-160.

Greenwood R. C., Burbine T. H., Miller M. F., and Franchi I. A. 2017. Melting and differentiation of early-formed asteroids: The perspective from high precision oxygen isotope studies. Chemie der Erde-Geochemistry 77:1-43.

Kitts K. and Lodders K. 1998. Survey and evaluation of eucrite bulk compositions. Meteoritics \& Planetary Science 33:A197-A213.

McSween H.Y., Mittlefehldt D.W., Beck A.W., Mayne R.G., McCoy T.J. (2010) HED Meteorites and Their Relationship to the Geology of Vesta and the Dawn 
Mission. In: Russell C., Raymond C. (eds) The Dawn Mission to Minor Planets

Miller M. F., Franchi I. A., Sexton A. S., and Pillinger C. T. 1999. High precision

$\Delta{ }^{17} \mathrm{O}$ isotope measurements of oxygen from silicates and other oxides:

Methods and applications. Rapid Communications in Mass Spectrometry 13:1211-1217.

Miller M. F. 2002. Isotopic fractionation and the quantification of ${ }^{17} \mathrm{O}$ anomalies in the oxygen three-isotope system: an appraisal and geochemical significance. Geochimica et Cosmochimica Acta 66:1881-1889.

Mittlefehldt D. W., Herrin J. S., Quinn J. E., Mertzman S. A., Cartwright J. A.,

Mertzman K. R., and Peng Z. X. 2013. Composition and petrology of HED polymict breccias: The regolith of (4) Vesta. Meteoritics \& Planetary Science 48:2105-2134.

Mittlefehldt D. W. 2015. Asteroid (4) Vesta: I. The howardite-eucrite-diogenite (HED) clan of meteorites. Chemie der Erde - Geochemistry 75:155-183.

Marshall D. 1996. Ternplot: An excel spreadsheet for ternary diagrams.

Computers \& Geoscience 22:697-699.

Morimoto N. 1988. Nomenclature of pyroxenes. Mineralogy and Petrology 39:55-76.

Moskovitz N. A., Willman M., Burbine T. H., Binzel R., P., and Bus S. J. 2010. inner Main Belt. Icarus 208:773-788. 
Papike J.J., Karner J.M., and Shearer C.K. 2003. Determination of planetary basalt parentage: A simple technique using the electron microprobe. American Mineralogist 88:469-472.Patzer A. and McSween H. Y. 2012. Ordinary (mesostasis) and not-so-ordinary (symplectites) late-stage assemblages in howardites. Meteoritics \& Planetary Science 47:1475-1490.

Pourkhorsandi H. 2018. Meteorites of Iran and hot deserts: classification and weathering. PhD Thesis, Aix-Marseille Université.

Pourkhorsandi H., Gattacceca J., Rochette P., D'Orazio M., Kamali H., de Avillez R., Letichevsky S., Djamali M., Mirnejad H., Debaille, and Jull A. J. T. 2019. Meteorites from the Lut Desert (Iran). Meteoritics \& Planetary Science 54:1737-1763.

Righter K. and Drake M. J. 1997. A magma ocean on Vesta: Core formation and petrogenesis of eucrites and diogenites. Meteoritics \& Planetary Science 32:929-944.

Seddiki A., Moine B., Cottin J. Y., Bascou J., Godard M., Faure F., BourotDenise M., and Remaci N. 2013. A mineralogical and geochemical study of polymict eucrite discovered in Sahara of southwest Algeria. Arabian Journal of Geosciences 6:3175-3184.

Starkey N. A., Jackson C. R. M., Greenwood R. C., Parman S., Franchi I. A., Jackson M., Fitton J. G., Stuart F.M., Kurz M., and Larsen L. M., 2016. Triple oxygen isotopic composition of the high ${ }^{3} \mathrm{He} /{ }^{4} \mathrm{He}$ mantle. Geochimica et Cosmochimica Acta 176:227-238. 
421 Takeda H. and Mori H. 1985. The polymict eucrites. 1985. The diogenite-

422 eucrite links and the crystallization history of a crust of their parent body.

423 Journal of Geophysical Research 90:C636-C648.

424 Vollmer C., Rombeck S., Roszjar J., Sarafian A. R., and Klemme S. 2020. The 425 brecciated texture of polymict eucrites: Petrographic investigations of 426 unequilibrated meteorites from the Antarctic Yamato collection. Meteoritics \& Planetary Science 55:558-574.

Walker R., Yin Q., and Heck P. 2018. Rapid effects of terrestrial alteration on highly siderophile elements in the Sutter's Mill meteorite. Meteoritics \& Planetary Science 53:1500-1506.

Warren P. H., Rubin A. E., Isa J., Gessler N., Ahn I., and Choi B. 2014. Northwest Africa 5738: Multistage alteration in an extraordinarily evolved eucrite. Geochimica et Cosmochimica Acta 141:199-227.

Wasson J. and Kallemeyn G. 1988. Compositions of chondrites. Philosophical Transactions of the Royal Society A: Mathematical, Physical and Engineering Sciences 325:535-544. variations and impact history of the Millbillillie eucrite. Meteoritics 29:237-245.

Zucolotto M. E., Tosi A. A., Villaca C. V.N., Moutinho A. L.R., Andrade D. P.P., 440 Faulstich F., Gomes A. M.S., Rios D. C., Rocha M. C. 2019. Serra Pelada: the 441 first Amazonian meteorite fall is a Eucrite (basalt) from asteroid 4-Vesta. Anais 442 da Academia Brasileira de Ciências 90:3-16. 
Tables:

444 Table 1: The analyzed pyroxene and plagioclase compositions (in wt\%) from Tintigny.

\begin{tabular}{|c|c|c|c|c|c|c|c|c|c|c|c|c|c|c|c|c|c|c|}
\hline Mineral & $\begin{array}{c}\text { Pyx } \\
\# 1\end{array}$ & $\begin{array}{c}\text { Pyx } \\
\# 2\end{array}$ & $\begin{array}{c}\text { Pyx } \\
\# 3\end{array}$ & $\begin{array}{l}\text { Pyx } \\
\# 4\end{array}$ & $\begin{array}{l}\text { Pyx } \\
\# 5\end{array}$ & $\begin{array}{c}\text { Pyx } \\
\# 6\end{array}$ & $\begin{array}{c}\text { Pyx } \\
\# 7\end{array}$ & $\begin{array}{l}\text { Pyx } \\
\# 8\end{array}$ & $\begin{array}{c}\text { Pyx } \\
\# 9\end{array}$ & $\begin{array}{l}\text { Pyx } \\
\# 10\end{array}$ & $\begin{array}{l}\text { Pyx } \\
\# 11\end{array}$ & $\begin{array}{l}\text { Pyx } \\
\# 12\end{array}$ & $\begin{array}{l}\text { Pyx } \\
\# 13\end{array}$ & $\begin{array}{l}\text { Pyx } \\
\# 14\end{array}$ & $\begin{array}{l}\text { Plg } \\
\# 1\end{array}$ & $\begin{array}{l}\text { Plg } \\
\# 2\end{array}$ & $\begin{array}{l}\mathrm{Plg} \\
\# 3\end{array}$ & $\begin{array}{l}\mathrm{Plg} \\
\# 4\end{array}$ \\
\hline $\mathrm{SiO}_{2}$ & 52.57 & 52.53 & 52.64 & 49.91 & 51.26 & 49.09 & 51.03 & 49.27 & 49.81 & 53.01 & 46.09 & 47.68 & 49.81 & 45.54 & 47.20 & 48.20 & 45.55 & 50.14 \\
\hline $\mathrm{Al}_{2} \mathrm{O}_{3}$ & 1.70 & 0.61 & 0.83 & 0.59 & 0.82 & 0.68 & 0.94 & 1.24 & 0.81 & 1.15 & 1.98 & 0.97 & 1.04 & 1.17 & 32.25 & 33.23 & 34.16 & 31.01 \\
\hline $\mathrm{TiO}_{2}$ & 0.26 & 0.15 & 0.11 & 0.39 & 0.51 & 0.42 & 0.20 & 0.47 & 0.71 & 0.15 & 1.11 & 0.74 & 0.67 & 0.92 & 0.00 & 0.00 & 0.01 & 0.03 \\
\hline $\mathrm{FeO}$ & 20.87 & 27.24 & 23.95 & 32.26 & 17.91 & 32.54 & 23.61 & 27.97 & 28.50 & 20.46 & 32.58 & 31.56 & 23.21 & 37.84 & 0.63 & 0.57 & 0.51 & 0.63 \\
\hline $\mathrm{Cr}_{2} \mathrm{O}_{3}$ & 0.84 & 0.22 & 0.61 & 0.23 & 0.31 & 0.30 & 0.93 & 0.41 & 0.35 & 0.74 & 0.24 & 0.21 & 0.33 & 0.18 & b.d.l. & b.d.I. & 0.01 & b.d.I. \\
\hline MnO & 0.76 & 0.74 & 0.86 & 1.06 & 0.45 & 0.91 & 0.85 & 0.88 & 0.88 & 0.74 & 0.87 & 0.82 & 0.75 & 1.03 & b.d.l. & 0.02 & 0.01 & 0.05 \\
\hline MgO & 19.40 & 17.28 & 17.69 & 10.33 & 10.51 & 12.96 & 17.50 & 10.72 & 11.49 & 20.84 & 5.37 & 7.88 & 8.77 & 2.58 & 0.06 & 0.02 & 0.05 & 0.04 \\
\hline $\mathrm{CaO}$ & 3.98 & 1.21 & 3.69 & 4.85 & 17.80 & 1.55 & 4.44 & 7.52 & 7.00 & 2.80 & 9.63 & 8.15 & 15.25 & 9.08 & 17.00 & 16.83 & 17.99 & 14.65 \\
\hline $\mathrm{Na}_{2} \mathrm{O}$ & 0.02 & 0.03 & 0.01 & 0.01 & 0.04 & b.d.l. & 0.01 & 0.07 & 0.07 & b.d.I. & 0.17 & 0.10 & 0.05 & 0.01 & 1.52 & 1.64 & 1.06 & 2.48 \\
\hline
\end{tabular}




\begin{tabular}{|c|c|c|c|c|c|c|c|c|c|c|c|c|c|c|c|c|c|c|}
\hline $\mathrm{K}_{2} \mathrm{O}$ & b.d.l. & 0.03 & 0.02 & 0.01 & 0.01 & 0.01 & b.d.l. & 0.02 & 0.02 & 0.01 & 0.01 & 0.05 & 0.01 & b.d.l. & 0.08 & 0.10 & 0.02 & 0.15 \\
\hline $\mathrm{NiO}$ & 0.05 & 0.06 & 0.03 & 0.03 & 0.07 & 0.15 & b.d.I. & 0.08 & 0.03 & 0.01 & 0.04 & b.d.I. & 0.07 & 0.07 & 0.01 & 0.01 & b.d.I. & 0.05 \\
\hline Total & $\begin{array}{c}100.4 \\
0\end{array}$ & $\begin{array}{c}100.1 \\
0\end{array}$ & $\begin{array}{c}100.4 \\
4\end{array}$ & 99.67 & 99.69 & 98.61 & 99.51 & 98.65 & 99.67 & 99.91 & 98.09 & 98.16 & 99.96 & 98.42 & 98.75 & $\begin{array}{c}100.6 \\
2\end{array}$ & 99.37 & 99.23 \\
\hline $\begin{array}{c}\text { En } \\
\text { (mol\%) }\end{array}$ & 57.1 & 51.7 & 52.4 & 32.4 & 31.5 & 40.1 & 51.6 & 33.7 & 35.3 & 60.7 & 17.6 & 25.1 & 26.8 & 8.5 & - & - & - & - \\
\hline $\begin{array}{c}\text { Fs } \\
\text { (mol\%) }\end{array}$ & 34.5 & 45.7 & 39.8 & 56.7 & 30.1 & 56.5 & 39.0 & 49.3 & 49.2 & 33.4 & 59.8 & 56.3 & 39.8 & 70.0 & - & - & - & - \\
\hline $\begin{array}{c}\text { Wo } \\
\text { (mol\%) }\end{array}$ & 8.4 & 2.6 & 7.9 & 10.9 & 38.4 & 3.4 & 9.4 & 17.0 & 15.5 & 5.9 & 22.6 & 18.6 & 33.5 & 21.5 & - & - & - & - \\
\hline $\mathrm{Fe} / \mathrm{Mn}$ & 27.1 & 36.3 & 27.5 & 30.1 & 39.3 & 35.3 & 27.4 & 31.4 & 32.0 & 27.3 & 37.0 & 38.0 & 30.6 & 36.3 & - & - & - & - \\
\hline $\mathrm{Fe} / \mathrm{Mg}$ & 0.6 & 0.9 & 0.8 & 1.7 & 1.0 & 1.4 & 0.8 & 1.5 & 1.4 & 0.6 & 3.4 & 2.2 & 1.5 & 8.2 & - & - & - & - \\
\hline $\begin{array}{c}\text { An } \\
\text { (mol\%) }\end{array}$ & - & - & - & - & - & - & - & - & - & - & - & - & - & - & 85.7 & 84.5 & 90.3 & 75.8 \\
\hline $\begin{array}{c}A b \\
\text { (mol\%) }\end{array}$ & - & - & - & - & - & - & - & - & - & - & - & - & - & - & 13.8 & 14.9 & 9.6 & 23.2 \\
\hline $\begin{array}{c}\text { Or } \\
\text { (mol\%) }\end{array}$ & - & - & - & - & - & - & - & - & - & - & - & - & - & - & 0.5 & 0.6 & 0.1 & 0.9 \\
\hline
\end{tabular}


446

447

448

449 
450 Table 2: Major and trace element composition of Tintigny eucrite.

451 Concentrations are reported in $\mathrm{mg} / \mathrm{g}$ and $\mu \mathrm{g} / \mathrm{g}$ for major and trace elements,

452 respectively.

\begin{tabular}{|c|c|c|c|c|c|}
\hline & Tintigny & RSD (\%) & BHVO-2 $^{1}$ & RSD (\%) & BVHO-2 $^{2}$ \\
\hline $\mathrm{Na}$ & 3.26 & 2 & 16.0 & 0.7 & 16.4 \\
\hline $\mathbf{M g}$ & 46.1 & 1 & 43.5 & 2 & 43.6 \\
\hline $\mathbf{A l}$ & 63.0 & 0.8 & 71.7 & 0.5 & 71.6 \\
\hline Si & 229 & 1 & 235 & 0.4 & 233 \\
\hline $\mathbf{P}$ & 0.206 & 1 & 1.17 & 2 & 1.2 \\
\hline $\mathrm{K}$ & 0.339 & 0.6 & 4.29 & 0.8 & 4.30 \\
\hline $\mathrm{Ca}$ & 68.3 & 0.7 & 81.3 & 1 & 81.7 \\
\hline$\overline{\mathrm{Ti}}$ & 3.78 & 1 & 16.4 & 1 & 16.3 \\
\hline $\mathrm{Cr}$ & 2.73 & 0.4 & 0.315 & 1 & 0.280 \\
\hline Mn & 4.21 & 1 & 1.33 & 1 & 1.3 \\
\hline $\mathbf{F e}$ & 142.3 & 1 & 89.1 & 0.4 & 86.3 \\
\hline $\mathbf{G a}$ & 2.63 & 12 & 22.57 & 1 & 21.7 \\
\hline $\mathbf{R b}$ & 0.351 & 49 & 8.35 & 5 & 9.80 \\
\hline $\mathrm{Sr}$ & 79.7 & 1 & 394 & 1 & 389 \\
\hline $\mathbf{Y}$ & 19.0 & 1 & 25.2 & 0.4 & 28.0 \\
\hline $\mathrm{Zr}$ & 49.6 & 1 & 162 & 1 & 172 \\
\hline $\mathrm{Nb}$ & 4.34 & 2 & 17.2 & 1 & 18 \\
\hline $\mathrm{Ba}$ & 34.4 & 2 & 134 & 1 & 130 \\
\hline La & 4.65 & 3 & 16.0 & 1 & 15.2 \\
\hline $\mathrm{Ce}$ & 10.5 & 0 & 37.6 & 1 & 38.0 \\
\hline Pr & 1.51 & 4 & 5.25 & 2 & 5.34 \\
\hline Nd & 7.04 & 3 & 24.1 & 3 & 25.0 \\
\hline
\end{tabular}




\begin{tabular}{|c|c|c|c|c|c|}
\hline $\mathbf{S m}$ & 2.09 & 5 & 6.18 & 4 & 6.20 \\
\hline $\mathbf{E u}$ & 0.660 & 2 & 2.10 & 2 & 2.07 \\
\hline $\mathbf{G d}$ & 2.91 & 2 & 6.40 & 3 & 6.30 \\
\hline $\mathbf{T b}$ & 0.490 & 2 & 0.910 & 1 & 0.940 \\
\hline $\mathbf{D y}$ & 3.32 & 2 & 5.34 & 2 & 5.31 \\
\hline $\mathbf{H o}$ & 0.727 & 1 & 0.994 & 3 & 1.04 \\
\hline $\mathbf{E r}$ & 2.08 & 4 & 2.52 & 4 & 2.54 \\
\hline $\mathbf{T m}$ & 0.310 & 3 & 0.337 & 8 & 0.335 \\
\hline $\mathbf{Y b}$ & 1.99 & 3 & 2.00 & 2 & 2.00 \\
\hline $\mathbf{L u}$ & 0.280 & 11 & 0.274 & 7 & 0.280 \\
\hline $\mathbf{H f}$ & 1.39 & 2 & 4.32 & 4 & 4.47 \\
\hline $\mathbf{T a}$ & 0.270 & 10 & 1.22 & 2 & 1.40 \\
\hline $\mathbf{T h}$ & 0.441 & 6 & 1.17 & 2 & 1.25 \\
\hline $\mathbf{U}$ & 0.121 & 3 & 0.407 & 5 & 0.412 \\
\hline $\mathbf{P b}$ & 0.162 & 17 & 0.769 & 1 & 1.65 \\
\hline $\mathbf{H H V O}$ & $b a 5 a l t$ & & & & \\
\hline
\end{tabular}

453 1: BHVO-2 basalt reference material analyzed during same session. ${ }^{2}$ :

$454{ }^{2}$ Compilled literature value from GeoReM database (http://georem.mpch$455 \quad$ mainz.gwdg.de/) 
Highlights

- Tintigny meteorite fell in February 1971 in a village in southern Belgium.

- Based on our multimethod study, we classified it as a polymict eucrite.

- This type of meteorites are achondrites from howardite-eucrite-diogenite (HED) clan.

- HED meteorites are believed to originate from the surface of the asteroid 4-Vesta.

- Tintigny is one of the 39 eucrite falls known to date. 


\section{AUTHORSHIP STATEMENT}

Manuscript title: Tintigny meteorite: the first Belgian achondrite

All persons who meet authorship criteria are listed as authors, and all authors certify that they have participated sufficiently in the work to take public responsibility for the content, including participation in the concept, design, analysis, writing, or revision of the manuscript. Furthermore, each author certifies that this material or similar material has not been and will not be submitted to or published in any other publication before its appearance in the Planetary and Space Science journal. 
Competing interests

The authors declare no competing interests. 